\title{
Characterization of a novel pathogenic variation c.1237T $>$ G in the FZD4 gene presenting new inheritance from an Iranian individual suffering vitreoretinopathy
}

\author{
Mina Zamani, ${ }^{1,2}$, Gholamreza Shariati ${ }^{3,2, *}$, Tahereh Seifi ${ }^{1,2}$, Alireza Sedaghat ${ }^{4,2}$, \\ Hamid Galehdari,* \\ ${ }^{1}$ Department of Genetics, Faculty of Sciences, Shahid Chamran University of Ahvaz, Ahvaz, Iran; \\ ${ }^{2}$ Narges Genetics Diagnostic Laboratory, Ahvaz, Iran; \\ ${ }^{3}$ Department of Genetics, Ahvaz Jundishapur University of Medical Sciences, Ahvaz, Iran; \\ ${ }^{4}$ Health Research Institute, Diabetes Research Center, Ahvaz Jundishapur University of Medical Sciences, Ahvaz, Iran.
}

SUMMARY Whole Exome Sequencing (WES) has been used increasingly in genetic determination of various known and unknown genetic disorders. Various genes are involved in the development of the vascular network of retina. Assessment of a collection of these genes could be provided by WES. Here we used WES for a patient suffering vitreoretinopathy to detect the disease causing variant. Sanger sequencing has been applied for variant verification and allelic segregation. After analysis of WES data we found a new variant c.1237T $>\mathrm{G}$ in the FZD4 locus which causes retinopathy of prematurity and exudative vitreoretinopathy (MIM number: 133780). Sanger sequencing showed this single nucleotide variation inherited as homozygous in the patient and heterozygous in her unaffected parents. Notably, bioinformatics analysis predicted the variant as disease causing and it has not been described yet in home datasets and public SNP databases. FZD4 mutations are mostly inherited as autosomal dominant traits. Our findings showed the first autosomal recessive inheritance of the FZD4 gene related retinopathy. On the other hand, our data shed light on the significance of an Exome sequencing application as a genetic test to identify and characterize the comprehensive spectrum of genetic variation and classification for patients with retinopathies.

Keywords exome sequencing, FZD4, vitreoretinopathy, autosomal recessive

\section{Introduction}

Familial retinopathy of prematurity and exudative vitreoretinopathy (MIM number: 133780) are rare disorders with retinal vascular development abnormalities which are inherited as autosomal dominant, autosomal recessive, or $\mathrm{X}$-linked traits. Clinical synopsis is asymmetric and variable (1). Although Symptoms of the diseases vary widely from mild signs to blindness, a remarkable hallmark is defective retinal angiogenesis, which causes retinal avascularity and subsequently depending on the ischemic rate causes hyperpermeable blood vessels, revascularization, vitreoretinal traction, retinal folds, and retinal detachment (2-4).

Occurring mutations in five genes cause vitreoretinopathy including; NDP, FZD4, LRP5, TSPAN12, and ZNF408 (1,4-9). Four of them including NDP, FZD4, LRP5, and TSPAN12 have a central role in Norrin/Frizzled4 signaling, and show a significant role for this pathway in retinal angiogenesis (10). Of these genes, FZD4 mutations are mostly inherited as autosomal dominant traits. This gene belongs to the frizzled gene family (seven-transmembrane domain receptors). They are receptors for Wnt proteins and norrin (NDP) and therefore contribute to vascularization of retina (1).

In recent years, next generation sequencing (NGS) has improved our knowledge about genetic and molecular bases of various spectrums of genetic disorders. With a multilateral vision, NGS, which has rapidly progressed has helped us to find out not only new disease causing variations but also new unreported inheritances, symptoms and has shed light on the way of knowing genetic roles (11-13).

Here we report a single nucleotide variation in an Iranian patient with retinopathy using Exome sequencing. We suggest that the FZD4 gene might be causative for both autosomal recessive as well as autosomal dominant vitreoretinopathy. 


\section{Patients and Methods}

\subsection{Case report}

Patient \& her parents were recruited from southwest Iran. The proband was a 20 -year-old girl with strabismus, horizontal nystagmus, decreased visual acuity, and retinal defects.

\subsection{Peripheral blood samples}

$10 \mathrm{~mL}$ of peripheral blood was withdrawn from each of the enrolled patient and her parents, which were collected in EDTA tubes.

\subsection{DNA extraction}

Genomic DNA was extracted using the standard salting out protocol. The quality and quantity of the extracted DNA samples were checked by gel electrophoresis and Nano-drop.

\subsection{Exome sequencing}

We applied whole Exome sequencing for the patient. Sample was subjected to Exome enrichment with the sure select $\mathrm{v} 6$ followed by sequencing using the Illumina HiSeq 2000 genome analyzer platform (CNAG).

\subsection{Sanger Validation}

PCR (Polymerase chain reaction) using primers designed by Oligo 7 with the forward 5-AACTGACTGGCTTGTGCTATG-3 and reverse primer TGATGCCCACCAACAAAGAC-3. The PCR was conducted using Master Mix (Amplicon, Denmark) amplified targeted region of the FZD 4 gene. PCR program was chosen as an initial denaturation at $95^{\circ} \mathrm{C}$ for $5 \mathrm{~min}, 35$ cycles of $95^{\circ} \mathrm{C}$ for $30 \mathrm{sec}$, annealing at $60^{\circ} \mathrm{C}$ for $30 \mathrm{sec}$, extension at $72^{\circ} \mathrm{C}$ for $30 \mathrm{~s}$, and a final extension at $72^{\circ} \mathrm{C}$ for $5 \mathrm{~min}$.

PCR products have directly been sequenced and analyzed using the ABI Prism 3700 automated genetic analyzer (Applied Biosystems). The results were analyzed with Chromas LITE 2.1.1, and then compared with the reference gene sequence using the CLUSTALW (Kyoto University Bioinformatics Center). Finally, the parent analysis and bi-directional sequencing confirmed the presence of the detected mutation.

\subsection{In-silico analysis}

There are many and various tools for prediction of pathogenicity of variations in genes coding and noncoding regions. In the present study, we used some of these tools for evaluation of disease causing potentiality of the present insertion variation.

\section{Results and Discussion}

\subsection{Clinical reports for the patient}

Patient belonged to Fars ethnicity of Iran and has a retinal disorder. The proband in family was a girl (IV2, Figure 1) 20 years of age. Parents (III-1 and III2, Figure 1) were related as first cousins. She was the only affected offspring of healthy parents who showed strabismus, horizontal nystagmus, decreased visual acuity and retinal defects. Left eye had no light perception and is unable to distinguish light from dark (NLP). In right eye vascular changes, aneurysmal telangiectasia, vascular leakage, eczema retinal, and tractional retinal detachment on the nasal side of the retina has been observed (Figure 2).

3.2. Sanger sequencing analysis of genomic amplification

Sanger sequencing validation and segregation check

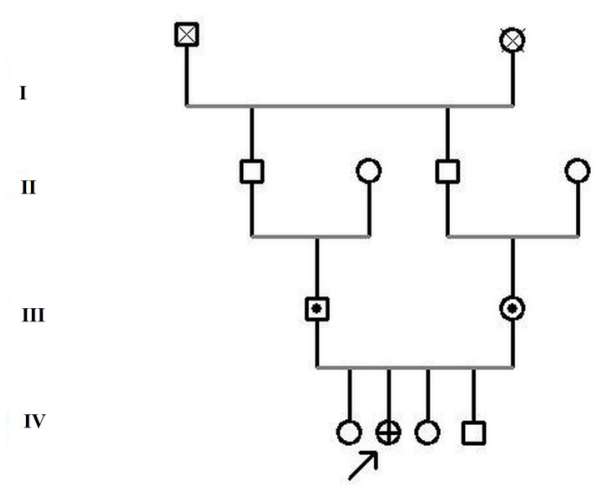

Figure 1. Family pedigree. Healthy father (III-1), healthy mother (III-2), and affected daughter (IV-2) are shown in the pedigree and the inheritance of eye disease seems to be autosomal recessive in the family.
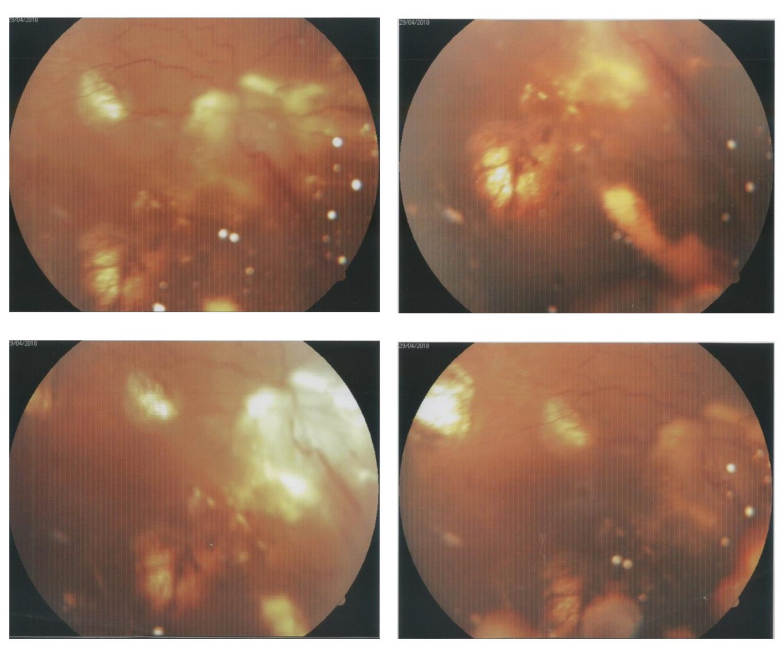

Figure 2. Fundoscopy images. Fundoscopy eyes of patient demonstrating vascular change eczema retinal, tractional retinal detachment. 
were used to verify selected variant (Figure 3 ).

Chromatograms (Figure 3) show parents are heterozygous and affected daughter is homozygous for c. $1237 \mathrm{~T}>\mathrm{G}$ (according to the genome assembly GRCh37/hg19) in FZD4.

\subsection{Variant characteristics}

Type and predicted pathogenicity of the variation using some pathogenesis evaluation tools are shown in Table 1. The variant was not found in public databases including EXAC and GenmeAD or also in our homemade database, which contains more than 900 exome files.

Figure 4 shows the variant located in second exon of FZD4 transcript, which is present in amino acid 413 of Fzd4 protein. Fzd4 is a transmembrane protein with
509 amino acids, which contains two domains including cd07448 (CRD_FZ4; Cysteine-rich Wnt-binding domain of the frizzled 4 (Fz4) receptor) and cd15038 (7tmF_FZD4; class F frizzled subfamily 4, member of 7-transmembrane $\mathrm{G}$ protein-coupled receptors) respectively formed by amino acids 42-167 and amino acids 209-509. The varied amino acid is located in TM helix 5 of cd15038.

The secondary structure of wild-type and mutant protein analysis was done using YASARA version 15.6.21 (14). The result showed the content of Fzd4 wild type including $55.5 \%$ helix, $4.6 \%$ sheet, $7.0 \%$ turn, $31.9 \%$ coil, $0.9 \% 3-10$ helix and $0.0 \%$ pi-helix are the same as mutant one (Figure 5).

Significantly gain of an allosteric site at R417 $(\mathrm{Pr}=$ $0.23, p=0.02)$ and altered trans-membrane protein $(\operatorname{Pr}=$

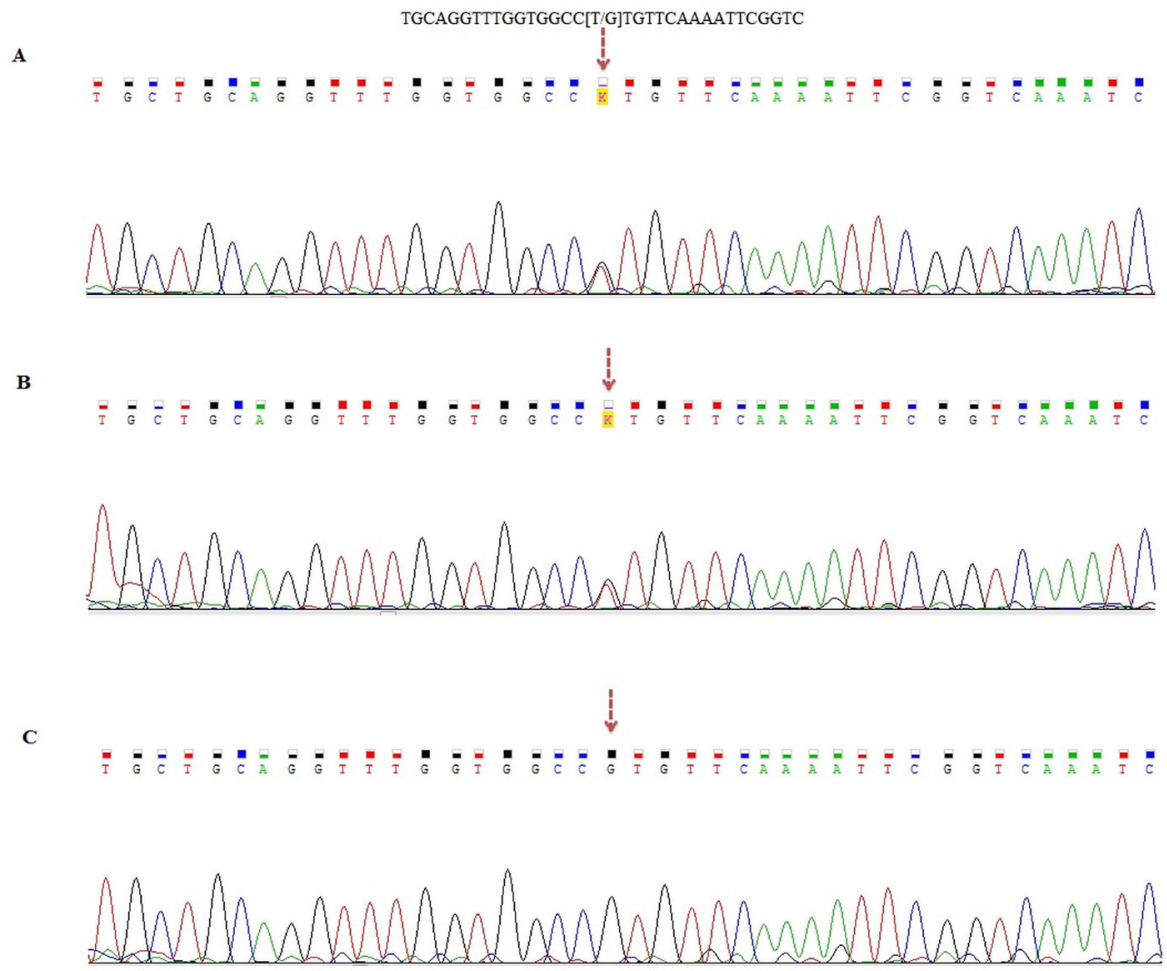

Figure 3. Chromatograms of the affected child and her parents' genome with focusing on the targeted region including the variation. (A), father (III-1 in pedigree); (B), Mother (III-2 in pedigree); and (C), affected daughter (IV-2 in pedigree), Arrows show the location of single nucleotide variation in FZD4, c. $1237 \mathrm{~T}>\mathrm{G}$.

Table 1. Location and predicted pathogenicity of the variation

\begin{tabular}{|c|c|c|c|c|c|c|}
\hline Patient & Gene & Type & Mutation & SIFT & Polyphen2 HDIV & Polyphen2 Hvar \\
\hline $\begin{array}{l}\text { IV-2 } \\
\text { (in Figure 1) }\end{array}$ & FZD4 & Missense & $\begin{array}{l}\text { g. } 3873 \mathrm{~T}>\mathrm{G} \\
\text { c. } 1237 \mathrm{~T}>\mathrm{G} \\
\text { cDNA.1543T }>\mathrm{G} \\
\text { p.L413V }\end{array}$ & $\begin{array}{l}0.001 \\
\text { Damaging } \\
\text { (cut-off }=0.05 \text { ) }\end{array}$ & $\begin{array}{l}1 \\
\text { Probably Damaging }\end{array}$ & $\begin{array}{l}0.997 \\
\text { Probably Damaging }\end{array}$ \\
\hline Mutation Taster & PredictSNP1 & PredictSNP2 & Proven & MutPred & Stability (I-Mutant v2.0) & Hydrophobicity (Peptide 2.0) \\
\hline $\begin{array}{l}0.9999992 \\
\text { Disease causing }\end{array}$ & $\begin{array}{l}61 \% \\
\text { Pathogenic }\end{array}$ & $63 \%$ Benign & $\begin{array}{l}-2.79 \\
\text { Deleterious } \\
\text { (cut-off }=-2.5 \text { ) }\end{array}$ & $\begin{array}{l}0.72 \\
\text { Pathgenic }\end{array}$ & Decrease & No difference \\
\hline
\end{tabular}


A

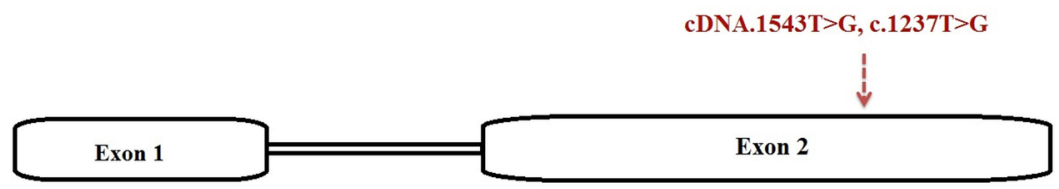

B

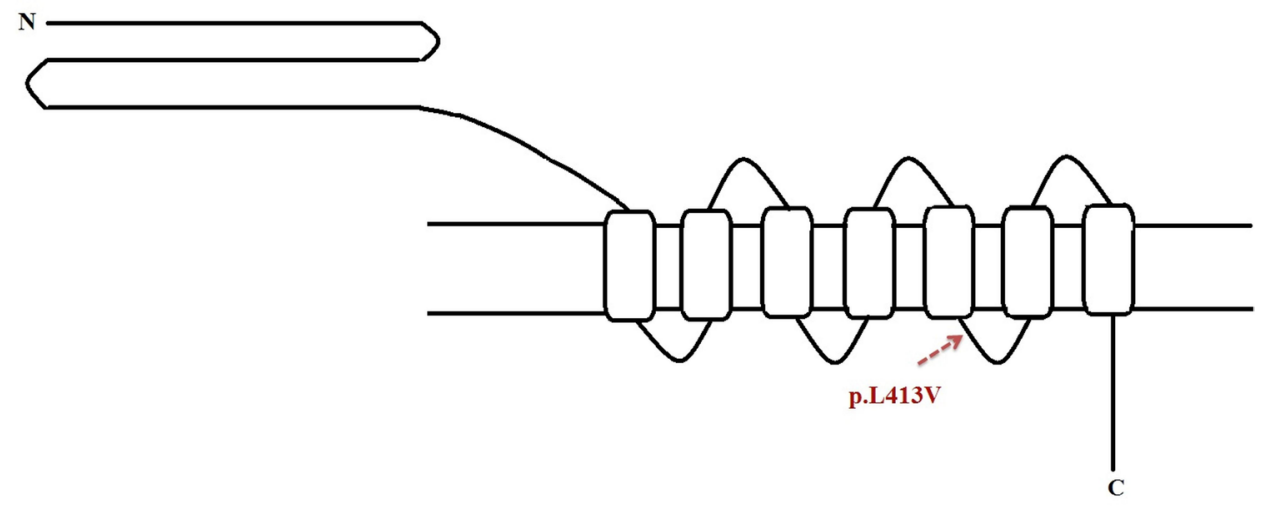

Figure 4. Schematic location of identified variation in (A) transcript and (B) protein of FZD4.
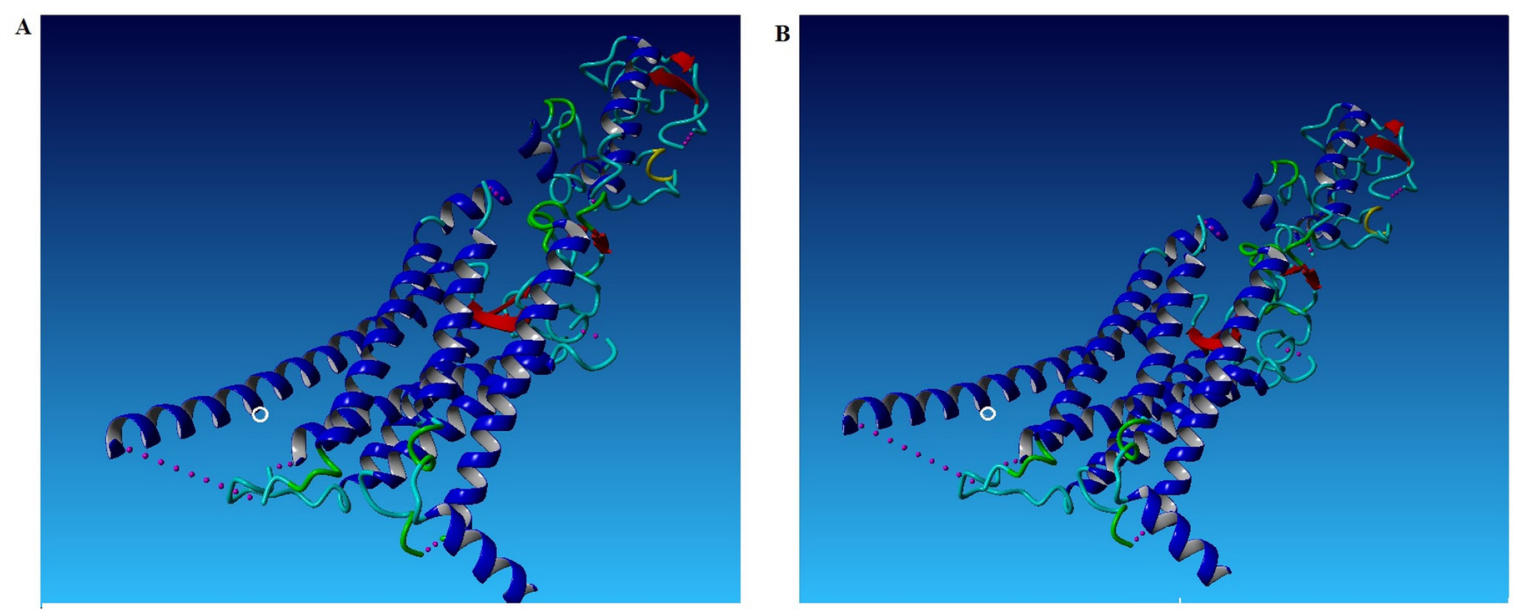

Figure 5. Secondary structure of (A) wild-type and (B) mutant Fzd4. Wight circles show varied amino acid location.

$0.01, p=0.01)$ could be potential effects of the variation according to the MutPred2 molecular mechanism prediction. Peptide 2.0 analysis results showed Hydrophobic: $47.49 \%$, Acidic: $8.57 \%$, Basic: 10.24\%, Neutral: $33.71 \%$ for both forms.

Vitreoretinopathy is a rare inherited disorder with phenotypic and genotypic variability. Although the main sign of disease is failure of peripheral retinal vascularization, it develops with variable symptoms ranging from asymptotic vascular defects to retinal detachments with blindness. Blood vessel formation developmentally is a remarkable process, which ensures growth and function ranging from cells to the entire organism. Wnt/Frizzled signaling has a central role in the development of the vascular network. To date, six genes have been reported to be a cause for vitreoretinopathy, including LRP5, FZD4, TSPAN12,
NDP, ZNF408, and KIF11. LRP5, FZD4, TSPAN12, NDP proteins are members of the Wnt/Norrin signaling pathway, which plays a critical role in eye development and angiogenesis. Mostly, mutations in one of the FZD4, the TSPAN12, the ZNF408, and the KIF11 genes causes autosomal dominant, LRP5 causes autosomal dominant and recessive, and NDP causes X-linked recessive and dominant forms of vitreoretinopathy $(1,2,7,15-22)$.

In the present study, a causative genetic mutation in an Iranian family was carried out by Whole Exome sequencing. Followed by data analysis, we identified a novel homozygous single nucleotide variation; c. $1237 \mathrm{~T}>\mathrm{G}$ in the FZD4 gene. Healthy parents were heterozygous for the detected change. To the best of our knowledge according to the OMIM (MIM number: 133780) and review of FZD4 related literature $(4,15,17,20-24)$ only autosomal dominant inheritance of vitreoretinopathy caused by mutations of the FZD4 gene 
have reported before. Condo et al. reported a 5-monthold baby carrying a homozygous change (p.R417Q) for which both parents harboring the same mutation heterozygously exhibited mild phenotypes, suggesting an autosomal dominant mode of inheritance with variable expressivity (15).

The result of in-silico analysis using mutation taster, Polyphen2, SIFT, MutPred2, PredictSNP2, proved this variant is disease causing. In addition, the identified variant is not present in our homemade exome database, which contains 800 samples, or in public SNP databases, including dbSNP, the Exome Aggregation Consortium (ExAC), and the NHLBI GO Exome Sequencing Project (ESP). Peterson et al. showed that FZD6 dimerizes and the dimer interface of FZD6 is formed by trans-membrane $\alpha$-helices four and five (25). They demonstrated that some mutations of TM5 decrease affinity between the TM4/5 peptides. These variants located in cytoplasmic domain, very close to TM5 (formed by amino acids 390-410) of Fzd4 (Figure 4) possibly can effect affinity of its dimerization. Although YASARA analysis showed, secondary structure doesn't differ between wild-type and mutant (Figure 5), analysis of molecular mechanism changes underlying the variation by MutPred showed allosteric site at R417 is gained and trans-membrane protein features are altered. Notably variation of R417Q was reported before as a pathogenic allele, rs80358294 $(15,20,26)$. So the present identified variation (c.1237T $>$ G or p.L413V, table 1) can indirectly make a partly pathogenic effect by changes in the physicochemical characteristics of neighboring amino acids and total protein.

Finally, we conclude that the new variant c. $1237 \mathrm{~T}>\mathrm{G}$ is highly pathogenic with a new autosomal recessive pattern of inheritance first described for vitreoretinopathy. Here by using WES technology we present the unreported inheritance -autosomal recessivefor vitreoretinopathy as the result of mutation in FZD4. The knowledge of this report; emphasizes the potency of exome sequencing acquired data in discovering new aspects of genetic diseases, and provides evidence for the autosomal recessive vitreoretinopathy caused by mutation in the FZD4 gene of note and should be considered for molecular diagnosis of vitreoretinopathy by clinicians.

\section{Acknowledgements}

We would like to express our very great appreciation to the patient and her family. We acknowledge our colleagues from Narges Genetics laboratory, especially Sahar Sedighzadeh and Jawaher Zeighami who helped us for the manuscript revision.

\section{References}

1. Gilmour DF. Familial exudative vitreoretinopathy and related retinopathies. Eye (Lond). 2015; 29:1-14.

2. Fei P, Zhu X, Jiang Z, Ma S, Li J, Zhang Q, Zhou Y, Xu Y, Tai Z, Zhang L, Huang L, Yang Z, Zhao P, Zhu $X$. Identification and functional analysis of novel FZD4 mutations in Han Chinese with familial exudative vitreoretinopathy. Sci Rep. 2015; 5:16120.

3. Criswick VG, Schepens CL. Familial exudative vitreoretinopathy. Am J Ophthalmol. 1969; 68:578-594.

4. Robitaille J, MacDonald ML, Kaykas A, et al. Mutant frizzled-4 disrupts retinal angiogenesis in familial exudative vitreoretinopathy. Nat Genet. 2002; 32:326330.

5. Collin RW, Nikopoulos K, Dona M, et al. ZNF408 is mutated in familial exudative vitreoretinopathy and is crucial for the development of zebrafish retinal vasculature. Proc Natl Acad Sci U S A. 2013; 110:98569861.

6. Nikopoulos K, Gilissen C, Hoischen A, et al. Nextgeneration sequencing of a $40 \mathrm{Mb}$ linkage interval reveals TSPAN12 mutations in patients with familial exudative vitreoretinopathy. Am J Hum Genet. 2010; 86:240-247.

7. Toomes C, Bottomley HM, Jackson RM, et al. Mutations in LRP5 or FZD4 underlie the common familial exudative vitreoretinopathy locus on chromosome 11q. Am J Hum Genet. 2004; 74:721-730.

8. Poulter JA, Ali M, Gilmour DF, et al. Mutations in TSPAN12 cause autosomal-dominant familial exudative vitreoretinopathy. Am J Hum Genet. 2016; 98:592.

9. Chen ZY, Battinelli EM, Fielder A, Bundey S, Sims K, Breakefield XO, Craig IW. A mutation in the Norrie disease gene (NDP) associated with X-linked familial exudative vitreoretinopathy. Nat Genet. 1993; 5:180-183.

10. Wang Y, Rattner A, Zhou Y, Williams J, Smallwood PM, Nathans J. Norrin/Frizzled4 signaling in retinal vascular development and blood brain barrier plasticity. Cell. 2012; 151:1332-1344.

11. Gupta S, Chatterjee S, Mukherjee A, Mutsuddi M. Whole exome sequencing: Uncovering causal genetic variants for ocular diseases. Exp Eye Res. 2017; 164:139-150.

12. Stranneheim H, Wedell A. Exome and genome sequencing: a revolution for the discovery and diagnosis of monogenic disorders. J Intern Med. 2016; 279:3-15.

13. Zhu X, Petrovski S, Xie P, et al. Whole-exome sequencing in undiagnosed genetic diseases: interpreting 119 trios. Genet Med. 2015; 17:774-781.

14. Krieger E, Vriend G. YASARA View - molecular graphics for all devices - from smartphones to workstations. Bioinformatics. 2014; 30:2981-2982.

15. Kondo H, Hayashi H, Oshima K, Tahira T, Hayashi K. Frizzled 4 gene (FZD4) mutations in patients with familial exudative vitreoretinopathy with variable expressivity. Br J Ophthalmol. 2003; 87:1291-1295.

16. Drenser KA, Dailey W, Vinekar A, Dalal K, Capone A, Jr, Trese MT. Clinical presentation and genetic correlation of patients with mutations affecting the FZD4 gene. Arch Ophthalmol. 2009; 127:1649-1654.

17. Toomes C, Bottomley HM, Scott S, Mackey DA, Craig JE, Appukuttan B, Stout JT, Flaxel CJ, Zhang K, Black GC, Fryer A, Downey LM, Inglehearn CF. Spectrum and frequency of FZD4 mutations in familial exudative vitreoretinopathy. Invest Ophthalmol Vis Sci.. 2004; 45:2083-2090.

18. Salvo J, Lyubasyuk V, Xu M, Wang H, Wang F, Nguyen D, Wang K, Luo H, Wen C, Shi C, Lin D, Zhang K, Chen R. Next-generation sequencing and novel variant 
determination in a cohort of 92 familial exudative vitreoretinopathy patients. Invest Ophthalmol Vis Sci. 2015; 56:1937-1946.

19. Robitaille JM, Zheng B, Wallace K, et al. The role of Frizzled-4 mutations in familial exudative vitreoretinopathy and Coats disease. Br J Ophthalmol. 2011; 95:574-579.

20. Qin M, Hayashi H, Oshima K, Tahira T, Hayashi K, Kondo H. Complexity of the genotype-phenotype correlation in familial exudative vitreoretinopathy with mutations in the LRP5 and/or FZD4 genes. Hum mutat. 2005; 26:104-112.

21. MacDonald ML, Goldberg YP, Macfarlane J, Samuels ME, Trese MT, Shastry BS. Genetic variants of frizzled-4 gene in familial exudative vitreoretinopathy and advanced retinopathy of prematurity. Clin Genet. 2005; 67:363-366.

22. Nallathambi J, Shukla D, Rajendran A, Namperumalsamy P, Muthulakshmi R, Sundaresan P. Identification of novel FZD4 mutations in Indian patients with familial exudative vitreoretinopathy. Mol Vis. 2006; 12:1086-1092.

23. Nikopoulos K, Venselaar H, Collin RW, et al. Overview of the mutation spectrum in familial exudative vitreoretinopathy and Norrie disease with identification of 21 novel variants in FZD4, LRP5, and NDP. Hum Mutat. 2010; 31:656-666.

24. Yoshida S, Arita R, Yoshida A, Tada H, Emori A, Noda Y, Nakao S, Fujisawa K, Ishibashi T. Novel mutation in
FZD4 gene in a Japanese pedigree with familial exudative vitreoretinopathy. Am J Ophthalmol. 2004; 138:670-671.

25. Petersen J, Wright SC, Rodríguez D, Matricon P, Lahav N, Vromen A, Friedler A, Strömqvist J, Wennmalm S, Carlsson J, Schulte G. Agonist-induced dimer dissociation as a macromolecular step in $\mathrm{G}$ protein-coupled receptor signaling. Nat Commun. 2017; 8:226.

26. Kondo H, Qin M, Tahira T, Uchio E, Hayashi K. Severe form of familial exudative vitreoretinopathy caused by homozygous R417Q mutation in frizzled-4 gene. Ophthalmic Genet. 2007; 28:220-223.

Received September 23, 2019; Revised January 7, 2020; Accepted January 17, 2020

\section{*Address correspondence to:}

Hamid Galehdari, Department of Genetics, Faculty of Sciences, Shahid Chamran University of Ahvaz, Ahvaz, Iran. E-mail: galehdari187@yahoo.com

Gholamreza Shariati, Department of Genetics, Ahvaz Jundishapur University of Medical Sciences, Ahvaz, Iran, and Narges Genetics Diagnostic Laboratory, Ahvaz, Iran.

E-mail: shariatig@yahoo.com

Released online in J-STAGE as advance publication February 4,2020 . 